Association for Information Systems AIS Electronic Library (AISeL)

CONF-IRM 2009 Proceedings

International Conference on Information Resources

Management (CONF-IRM)

$5-2009$

\title{
Restructuring in Telecommunications and its Market Impacts: An Event-Study Analysis
}

Vijay Sethi

Nanyang Technological University, avsethi@ntu.edu.sg

Sandip Chakraborty

SP Jain Center of Management, sandip.chakraborty@spjain.org

Neerja Sethi

Nanyang Technological University, aneerja@ntu.edu.sg

Follow this and additional works at: http://aisel.aisnet.org/confirm2009

\section{Recommended Citation}

Sethi, Vijay; Chakraborty, Sandip; and Sethi, Neerja, "Restructuring in Telecommunications and its Market Impacts: An Event-Study Analysis" (2009). CONF-IRM 2009 Proceedings. 37.

http://aisel.aisnet.org/confirm2009/37 


\title{
37. RESTRUCTURING IN TELECOMMUNICATIONS AND ITS MARKET IMPACTS: AN EVENT-STUDY ANALYSIS
}

\author{
Vijay Sethi \\ Nanyang Technological University \\ avsethi@ntu.edu.sg \\ Sandip Chakraborty \\ SP Jain Center of Management \\ sandip.chakraborty@spjain.org \\ Neerja Sethi \\ Nanyang Technological University \\ aneerja@ntu.edu.sg
}

\begin{abstract}
The aim of the study is to present a detailed assessment of the major strategic changes in the telecommunications industry and their impact on market returns. Using a global sample of major telecom companies, significant events related to restructuring were identified and then assessed in terms of their favorable or unfavorable impacts. Based on the methodology of event-study analysis with GARCH specification, the impact of events was tested after incorporating dummy variables of different lengths (7, 15 and 20). Simultaneously, subsequent to a regression, Cumulative Abnormal Returns (CAR) were calculated within a variable event window of 7, 15 and 20 Days. Market returns were studied starting from 1996 until 2008. The results show interesting patterns in terms of how the market views restructuring in the business model of telecom companies, organizational structure, alliances and mergers, and technological platform changes. Countries differ significantly in how they view telecoms restructuring and what changes are considered beneficial by investor and which ones are not.
\end{abstract}

\section{Keywords}

Telecommunications Restructuring, Industry Changes, Event Study Analysis, GARCH, Cumulative Abnormal Returns.

\section{Introduction}

Telecommunications is largely ruled by big national and regional players in most countries. The forces of deregulation have opened-up most markets and the resulting competition has led to rapid innovation and increased reach in terms of area and percentage of population covered. The industry not only faces these competitive challenges, but is also seeing new platforms such as 
mobile that are threatening to completely overtake the traditional fixed-line business. Data communications, new innovations such as WiMax and IMS, and the like have left carriers with no choice but to change and restructure for this new world.

Increased customer choices and thus their increase bargaining power, and also the fact that most markets are quite saturated, have made it more difficult for the telecom operators to increase their Average Revenue per User. The churn rate is also high especially now with number portability in most markets. For the telecoms industry, it is turning out to be a price war with the customer being the sole winner. Companies are having to invest heavily in billing systems, providing better value added services, minimizing network downtime, and overall efficiencyfocused efforts.

In this rapidly changing and intensely-competitive industry, major strategic changes are a necessity and companies continuously need to change and to restructure in order to stay competitive. Players constantly need to revaluate their business model (Average revenue per user, charging rates, etc.), organizational form and structure (leadership changes, divestment of stakes), alliances and mergers (new acquisitions, partnerships), and of course technological platforms (new technology, innovations). Sometimes such restructuring can have a positive impact on market value while other changes are perceived negatively. This paper undertakes a systematic study of the major restructuring initiatives in global telecoms firms and assesses whether they have a positive or a negative stock market impact. The issue is important and critical as it provides insights into how company values will be impacted and what can telecoms companies do to ensure that restructuring does not lead to either a bubble-or-burst scenario vis-àvis stock prices.

\section{Past Research}

Two streams of research are most relevant for this study. The first is of the telecoms sector and the impact of strategic changes on the industry and its players. The second is the event-study approach that forms the methodology of the paper. The most salient work in these two streams is reviewed below.

A telecoms-study (Eisenach \& Lowengrab, 2003) that typifies the approach we have taken looked at the impact of the FCC's decision on the two telecommunications industry sectors: the Regional Bell Operating Companies, and the competitive local exchange carriers. Using several sources of information such as Lexis-Nexis, the Bureau of National Affairs' Daily Report for Executives, and Telecommunications Reports, salient decisions that had an impact on investors (by looking at reports on market expectations before and after a decision) were identified. Statistical tests were done to see if the estimated Adjusted Returns and Cumulative Adjusted Returns were truly related to the events at issue or generated by random movements in stock prices. The study concluded that the FCC's decision had a significant negative impact on the market capitalization of the Bell companies, reducing their going-forward value by approximately $\$ 19$ billion relatively.

Kushida (2005) similarly reiterates that the regulatory structures imposed by the governments and its policies are important determinants of the dynamics of the telecommunications sector. Further, since regulatory structures are different across countries, competitive dynamics thus 
vary across geographies. And this is turn influences market returns. The paper also notes that regulatory policies play a large role in the decision to introduce new technologies or other restructuring.

Another recent study (Cohen-Meidan, 2007) looked at the effect of standardization on competition in the US cable modem market. It examined the impact of firms' membership on two competing standardization groups: a commercial consortium (Multimedia Cable Network System Partners Ltd) and an official organization (the Institute of Electrical and Electronics Engineers working group IEEE 802.14). It showed significant market impacts and that investors are indeed influenced by technology choices on standards.

The stream of work based on the event-study approach is quite extensive. One that is particularly relevant is Singh et al. (2005) who explored the reasons for the survival of some Internet start-ups within the framework of organizational adaptation. It proposed that the performance of a firm in a fast-changing environment is related to the adaptability of its business model. Event-study methodology was used to assess the impact of 885 business model changes undertaken by 20 dot-coms. The results show that the market rewarded certain types of changes more favorably than others, and that firms could use market reactions to guide their IT investments.

In a similar vein, Sanchez-Lorda (2006) examined the stock market reaction to diversification and internationalization initiatives. The sample consisted of European telecom companies' M\&A and strategic alliances between 1986 and 2001. It showed that the market reaction depends on the geographical and business scope of the initiatives.

There are many other studies that have used the event-based approach. They include Aggarwal et al. (2006) who assessed the effects of XML standardization on stock price of IT companies; Bailey et al.'s (2004) study of the market responses to earnings announcement in Singapore and Thailand; Madden et al.'s (2006) look at the impact of marketing on firms' performance; and Roy (2002) who examined the extent of market efficiency arising from the release of disclosures about market regulation

As compared to most of the past studies, our research is more comprehensive both substantively and also methodologically. In terms of the latter, the trend has been to use the student's t-test to assess a stock's abnormal returns for pre and post-announcement periods. What is missing is a consideration of such issues as linear/non-linear autocorrelations and volatility clustering of asset returns (Cont, 2001). That is why we have treated asset returns as conditionally heteroskedastic with a GARCH type of a stochastic process. From a domain perspective, our sample comes from multiple countries and in fact is one of the few studies that have looked at the telecoms vertical in totality to understand how dynamic changes in it are affecting market value. Given this more rigorous treatment, our results may hold important insights not only for the telecoms sector but also others where companies are large and operate in a global context. 


\section{Research Methodology}

Our sample consisted of 36 telecoms companies from the regions of Australia, Brazil, China, France, Germany, India, Japan, New Zealand, South Africa, Singapore, Spain, United States and United Kingdom. All the companies we selected had to be listed on their respective stock exchanges.

Using the websites of the telecom service providers and news articles, major company events were collected. The data included details of the event and its announcement date. The sample was then pared down to those events which could be classified under one of the following 4 major types of restructuring:

- Alliances/Acquisitions

- Corporate Model (structure, leadership)

- Business Model (new rate plans, new pricing strategies)

- Technology Development

More than 200 events qualified under the above criteria and they pertained to 19 companies (from the initial sample of 36), as listed below under Results.

\subsection{Data Analysis}

Using secondary sources, the mean daily closing prices of stocks and corresponding closing prices of market indices were collected. Returns were calculated for both the stock prices and market index using the formula below:

$$
\mathrm{Rt}=\ln (\mathrm{Pt} / \mathrm{Pt}-1)
$$

Rt is Returns for day t; In is Natural Logarithm; Pt is Price of Stock at day t; Pt-1 is Price of stock at day $t-1$.

\subsubsection{Event Study Analysis - Phase 1}

Unlike other studies, we followed a two-part analysis scheme. In Phase 1, we first identified those events that were actually significant, and in Phase 2 then assessed their positive or negative impacts. Such an approach is more systematic and allows for a more rigorous examination of the data.

First, a stochastic analysis was done for each of the collected events. Since the data was marketreturns based on the log normal of prices over a period of 10 years or more, its volatility was non-constant and conditionally heteroskedastic. Hence, we used the GARCH estimation of individual stock returns after controlling for linear and non-linear autocorrelation in that particular stock's return, return of market index, and dummy variables controlling for event induced effects. We also calculated the Cumulated Abnormal Returns (CAR) to verify that the event actually led to a market reaction in terms of stock prices.

Abnormal returns (AR) are the mathematical difference between actual returns and the normal or expected returns. A time-series regression with a Generalized Autoregressive Conditionally Heteroskedastic (GARCH) (Bollerslev, 1986) takes into account certain important characteristics of market models for security prices, i.e., stochastic and time-varying non-diversifiable risk, and a time-varying heteroskedastic error structure ${ }^{i}$. The event study is then based on the cumulative sums of standardized one-step-ahead forecast errors (based upon the stochastic and GARCH 
error market model) in order to assess the direction and magnitude of how a particular event affects the market.

The following equations formed the basis of our analysis,

$$
\begin{aligned}
& R_{t}^{i}=\phi_{0}+\varphi_{1} R_{t-1}^{i}+v R_{t-1}^{*}+\sum_{i=1}^{3} \lambda_{i} D_{i}+a_{t} \\
& a_{t}=\sigma_{t} \eta_{t} \\
& \sigma_{t}^{2}=k+\alpha a_{t-1}^{2}+\beta \sigma_{t-1}^{2}
\end{aligned}
$$

- $\quad R_{t}^{i}$ the continuously compounded is return of security ' $\mathrm{i}$ ' at day ' $\mathrm{t}$ ', $R_{t-1}^{*}$ is the continuously compounded return to the value weighted market portfolio at day ' $\mathrm{t}$ ', $D_{i}$ is a dummy variable $=1$ ( $\mathrm{i}=7$ days $),=2(\mathrm{i}=15$ days $),=3$ ( $\mathrm{i}=20$ days) and zero elsewhere.

- $\sigma_{t}^{2} \mid F_{t-1}$ is the conditional variance at information set available at 't-1', $\boldsymbol{F}_{t-1}$, i.e., $E\left(a_{t}^{2} \mid F_{t-1}\right)=\sigma_{t}^{2}, v_{t} \sim \operatorname{NIID}\left(0, \sigma_{v}^{2}\right)$ and $\varepsilon_{t} \sim \operatorname{NIID}\left(0, \sigma_{\varepsilon}^{2}\right), \eta_{t}$ follows either Gaussian IID process, $\alpha+\beta<1$

\subsubsection{Model Estimation}

The estimation of $\operatorname{GARCH}(1,1)$ model is done through Maximum Likelihood technique with Gaussian innovations. For estimation the $\operatorname{GARCH}(1,1)$ model can be rewritten as: $\sigma_{t}^{2}=k+\alpha a_{t-1}^{2}+\beta \sigma_{t-1}^{2}$

$\Leftrightarrow \sigma_{t}^{2}=(1-\beta L)^{-1}\left(k+\alpha a_{t-1}^{2}\right)=\left(1+\beta L+\beta^{2} L^{2}+\ldots\right)\left(k+\alpha a_{t-1}^{2}\right)$

where $\mathrm{L}$ is the lag operator.

Therefore $\sigma_{t}^{2}$ depends on all the past values of $a_{t}^{2}$. To evaluate $\sigma_{t}^{2}$ from this equation it is assumed that $a_{t}^{2}, \sigma_{t}^{2}=0 \forall t \leq 0$. For the optimization of log-likelihood function the following approximation is done:

$$
\begin{aligned}
& \sigma_{1}^{2^{*}}=k \\
& \sigma_{2}^{2^{*}}=k+\alpha a_{1}^{2}+\beta \sigma_{1}^{2^{*}}
\end{aligned}
$$

:

Given that $a_{t} \mid F_{t-1} \sim N\left(0, \sigma_{t}^{2}\right)$ with probability density function

$f\left(a_{t} \mid F_{t-1}\right)=\left(2 \pi \sigma_{t}^{2}\right)^{-1 / 2} \exp \left(-\frac{1}{2 \sigma_{t}^{2}} a_{t}^{2}\right)$ where

$\sigma_{t}^{2}=(1-\beta L)^{-1}\left(k+\alpha a_{t-1}^{2}\right)=\left(1+\beta L+\beta^{2} L^{2}+\ldots\right)\left(k+\alpha a_{t-1}^{2}\right)$

The log-likelihood function for conditional joint distribution of innovations, $a_{t} s$ is given by $\operatorname{Ln}\left[f\left(a_{n}, a_{n-1}, \cdots, a_{1} \mid a_{0}\right)\right]=\sum_{t=1}^{n} \operatorname{Ln}\left[f\left(a_{t} \mid F_{t-1}\right)\right]=-\frac{n}{2} \operatorname{Ln}(2 \pi)+\sum_{t=1}^{n}-\frac{1}{2} \operatorname{Ln}\left(\sigma_{t}^{2}\right)-\frac{1}{2} \sum_{t=1}^{n} \frac{a_{t}^{2}}{\sigma_{t}^{2}}$ The above log-likelihood function can be maximized with respect to argument vector, 
$\left[\phi_{0}, \phi_{1}, v, \lambda_{i}, k, \alpha, \beta\right]$ such that $\frac{\partial \operatorname{Ln}[f(.)]}{\partial\left[\phi_{0}, \phi_{1}, v, \lambda_{i}, k, \alpha, \beta\right]}=0$

The Dummy variables that were considered were for $+7,+15$ and +20 . The data was analysed using S+Finmetrics. The schematic detailing the analysis process is presented below in Figure 1 :

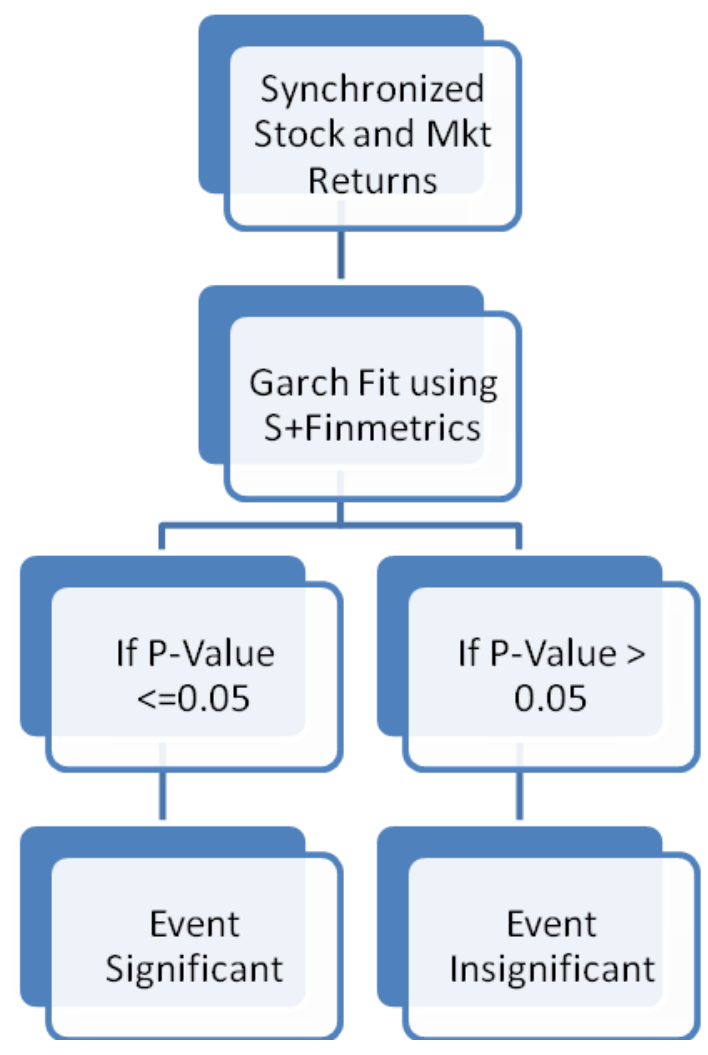

Figure 1: Event-Study Phase 1 Analysis

\subsubsection{Event Study Analysis - Phase 2}

Out of 200+ events, 44 were found to be significant. To test them, cumulated abnormal returns (CAR) were calculated to verify the effect of market reactions. The change in CAR pre- and post-event verified that the market reactions were positive or negative. Figure 2 shows the analysis process that was followed in this phase. 


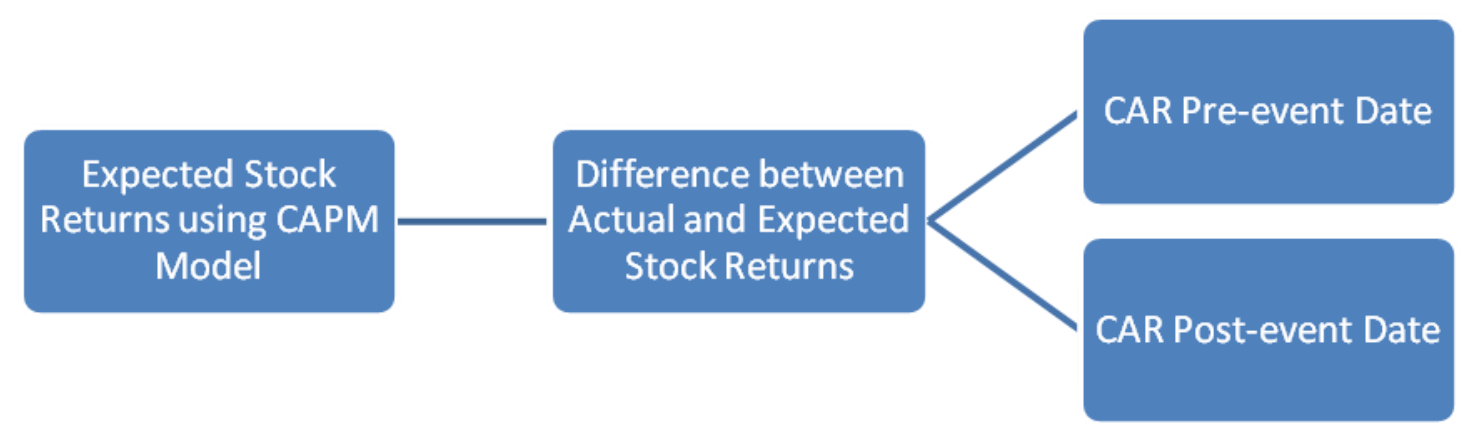

Figure 2: Event-Study Phase 2 Analysis

\section{Results}

Table 1 shows the 19 companies whose restructuring events were significant. It also lists the period over which the restructuring took place and other geographic details.

\begin{tabular}{|llll|}
\hline Company & Country & Index & Period \\
\hline AT\&T & USA & NYSE & $1995-2008$ \\
Sprint Nextel & USA & NYSE & $1995-2008$ \\
Qwest & USA & NYSE & $1995-2008$ \\
China Telecom & China & Hang Seng HESK & $2002-2008$ \\
China Unicom & China & Hang Seng HESK & $2000-2008$ \\
China Mobile Ltd & China & Hang Seng HESK & $1997-2008$ \\
Vodafone UK & UK & FTSE-100 LSE & $1995-2008$ \\
Deutsche Telekom & Germany & DAX & $1996-2008$ \\
Telstra & Australia & S\&P ASX-100 & $1997-2008$ \\
Softbank Corp & Japan & TOPIX & $1998-2008$ \\
KDDI Corporation & Japan & TOPIX & $1998-2008$ \\
NTT Corp & Japan & TOPIX & $1998-2008$ \\
Bharti Airtel & India & BSE Sensex & $2002-2008$ \\
MTNL & India & BSE Sensex & $1995-2008$ \\
Singtel & Singapore & SGX & $1995-2008$ \\
Mobileone Ltd & Singapore & SGX & $1995-2008$ \\
Telecom NZ & New Zealand & NZX & $1995-2008$ \\
FASTWEB & Italy & Mibtel-Milan & $2000-2008$ \\
Telecom Italia & Italy & Mibtel-Milan & $1995-2008$ \\
\hline
\end{tabular}

Table 1: Telecom Companies with Significant Restructuring Events

Figure 3 shows the distribution of events which had a significant market impact - either positive or negative. Thirty eight percent of all events pertained to Business Model changes and $31 \%$ to Technology initiatives. Alliances/Mergers constituted only $15 \%$ of events while Corporate 
Restructuring comprised $16 \%$. In other words, markets are twice as likely to react to changes in business products/services and to how they are delivered through different technology platforms that they are to corporate shake-ups or to alliances and mergers.

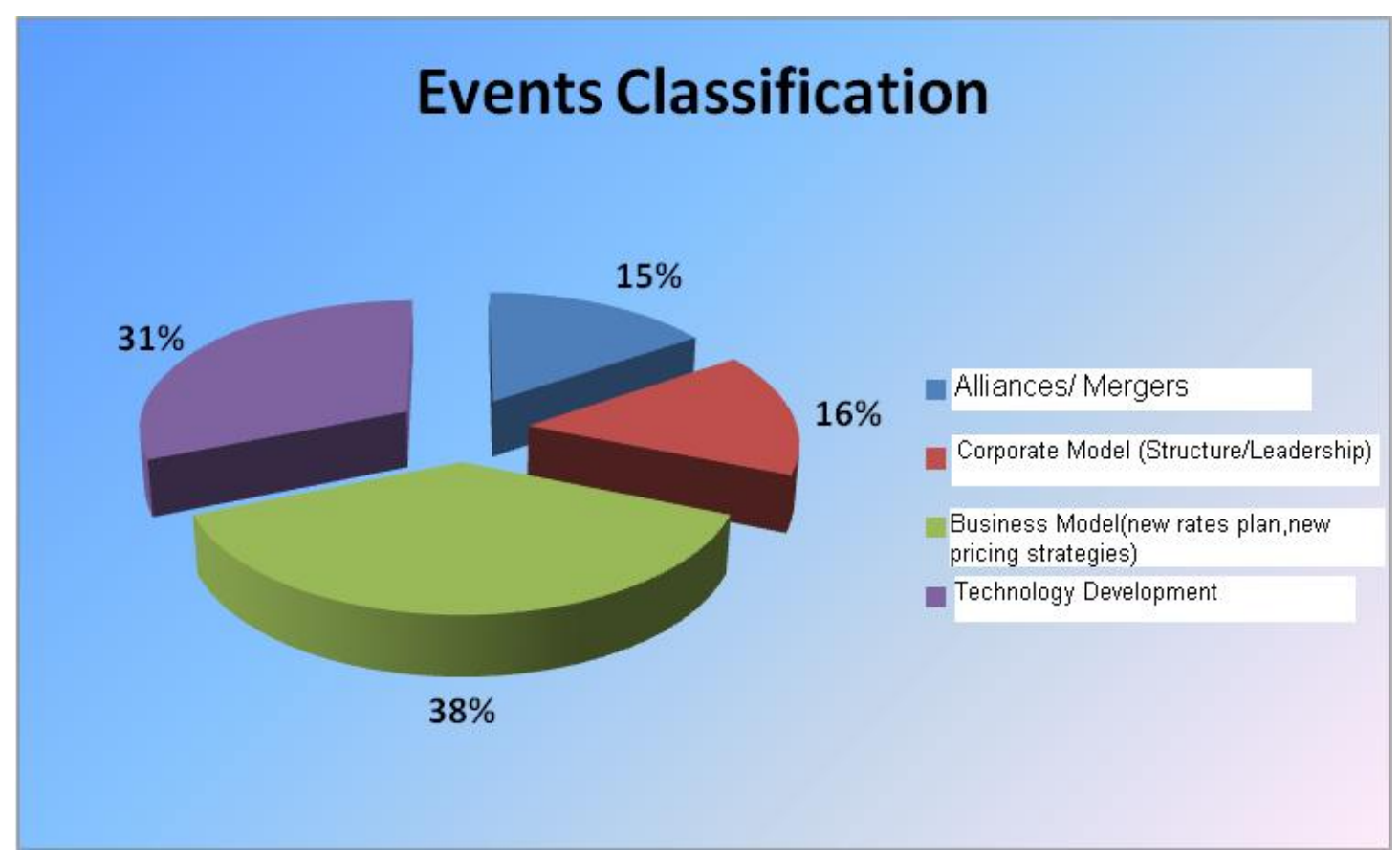

Figure 3: Events with Significant Market Reactions

Figure 4 shows the distribution of significant events across various countries and there are many interesting patterns. Technology initiatives lead to investor reactions in most countries, more so than other types of restructuring. Some markets are also quite conscious of M\&A activities, especially US, Italy, and Singapore. In most of the bigger economies (US, China, Germany, Japan), corporate restructuring has a significant impact, while business model changes are uniformly perceived to be significant everywhere.

Figures 5-8 shows the proportion of events in each of the four categories that had a positive or negative impact. Thus, $71 \%$ of all Business Model changes had a positive impact on the market. In contrast, only $56 \%$ of M\&A, $29 \%$ of Corporate Changes, and $21 \%$ of Technology changes had a positive impact. 


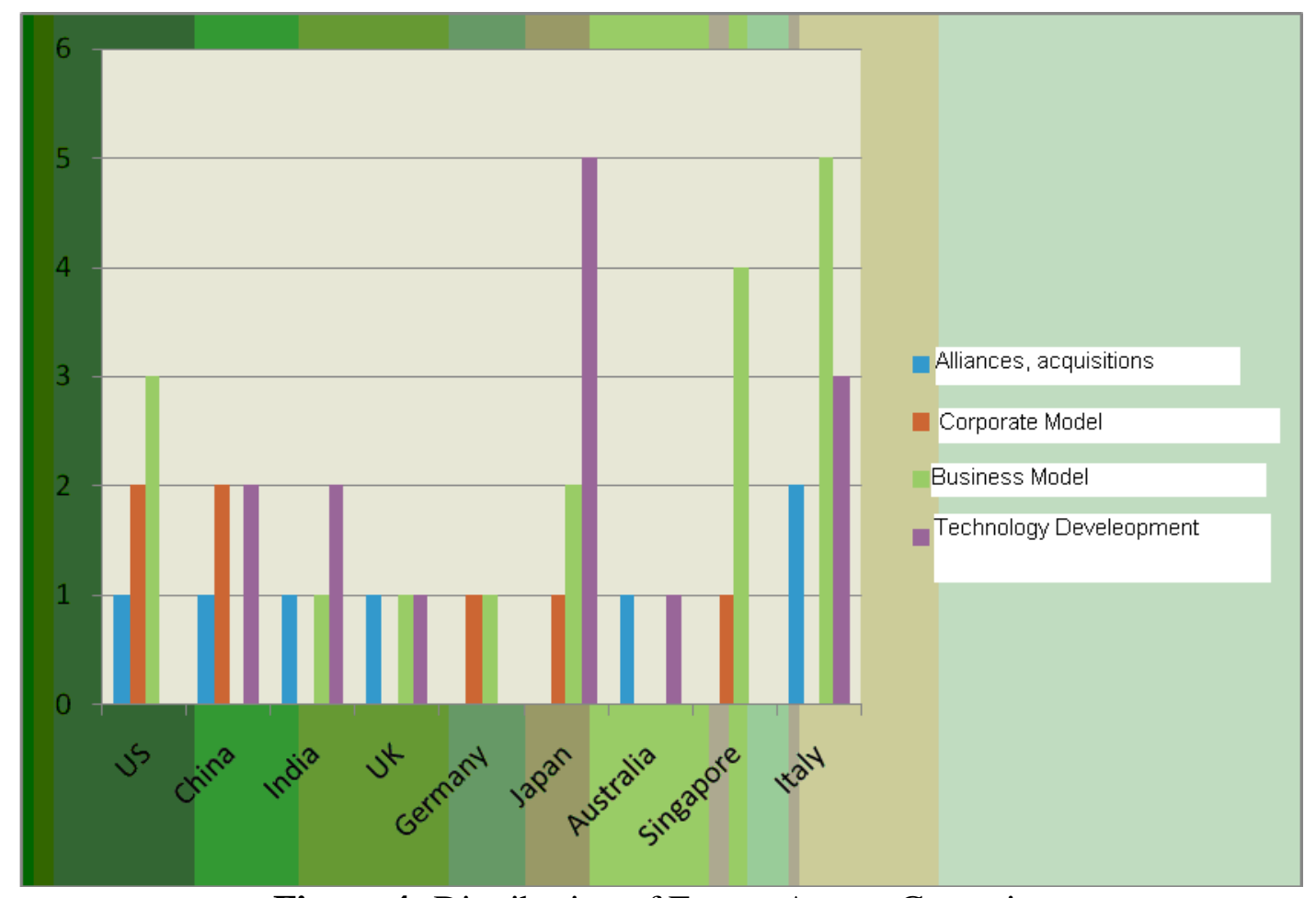

Figure 4: Distribution of Events Across Countries

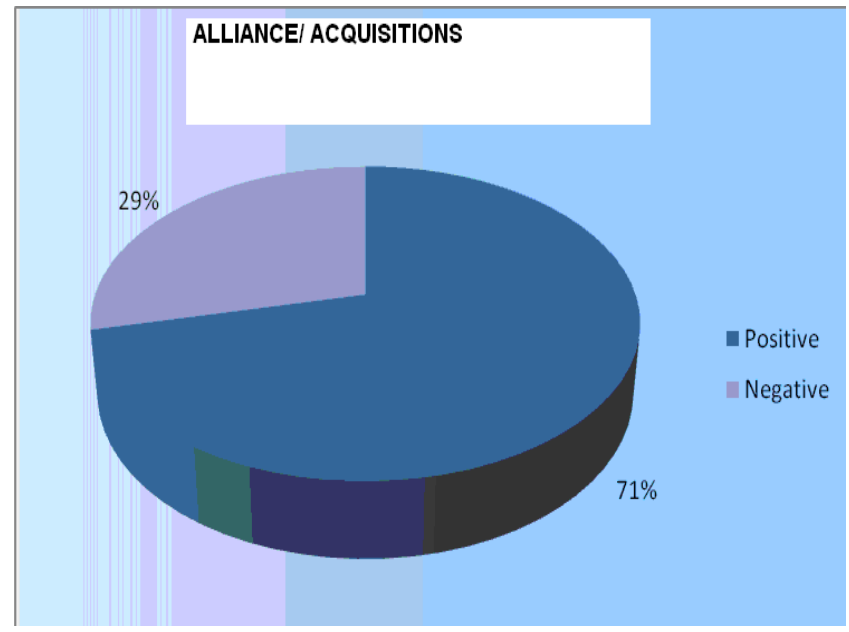

Figure 5: Market Impact of Alliance/Acquisitions Activities

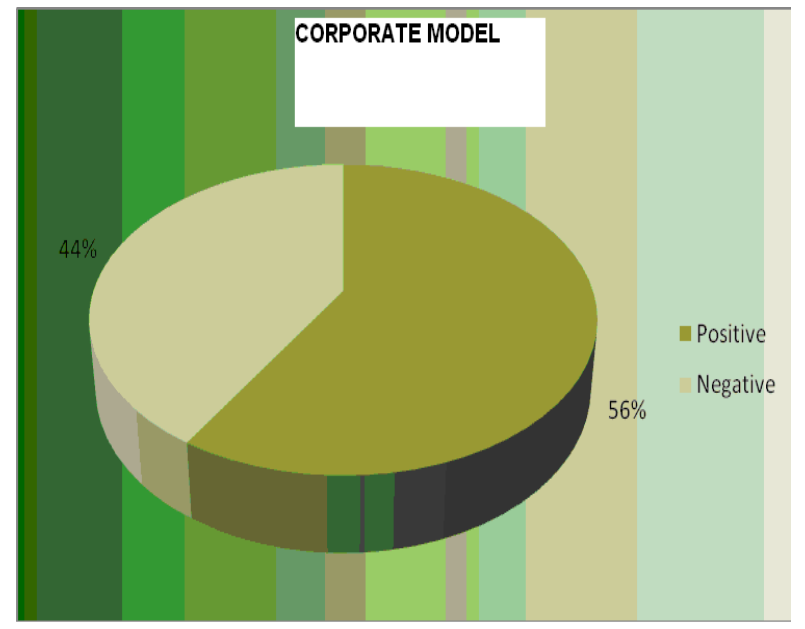

Figure 6: Market Impact of Corporate Model Activities 


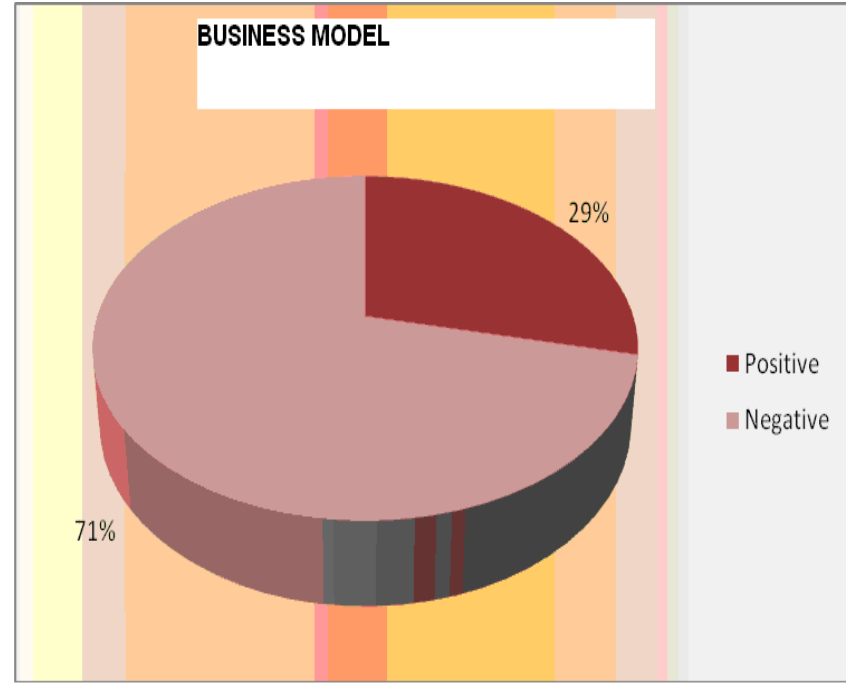

Figure 7: Market Impact of Busines Model Activities

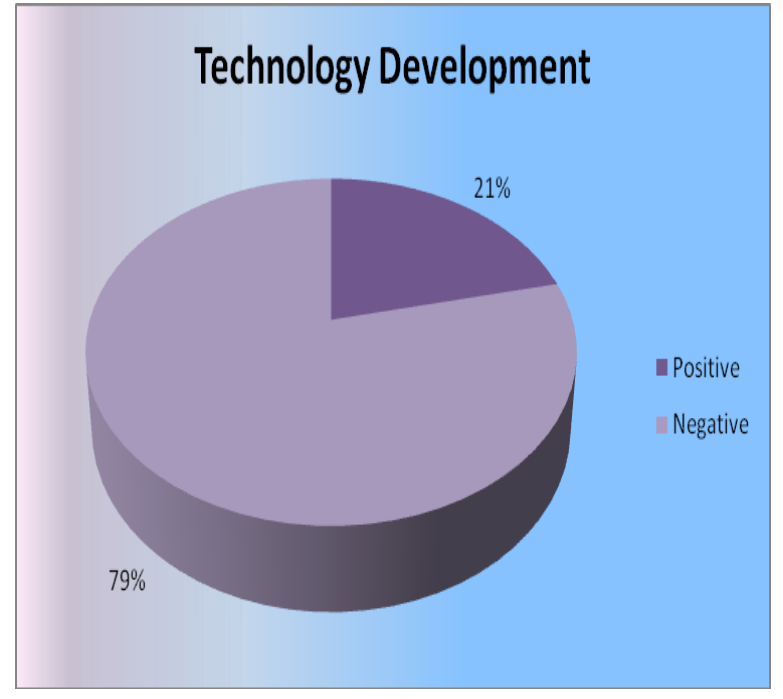

Figure 8: Market Impact of Technology Development Activities

\section{Conclusion}

The nature of the telecoms business makes it imperative that companies pay attention to their technology infrastructure as major changes in this area will be scrutinized and affect the market, more so than other types of restructuring. The caveat though is that most technology changes are viewed negatively. This means the market is generally wary of new investments in platforms or standards perhaps because as it may lead to increased costs. The implication is that companies need to better justify such investments either as drivers of new revenue sources or to reduce total costs. In this regard, perhaps we can learn from the Italian market where 2 out of 3 technology events have a positive impact (in contrast, for example, to Japan where 3 out of every 5 technology events elicit a negative reaction).

Changes to the Business Model, such as new pricing schemes or new products and services, also catch the eye of the market but, unlike technology events, they are viewed more favorably. In fact, almost one third of such changes have a positive impact. Once again, this still means that more can be done by companies to justify and explain the benefits of such changes. Given that such benefits are more obvious and easily observable, it may imply a credibility issue. Companies should thus ensure that they provide adequate rationale and evidence to the market about the benefits from making business model changes and their top or bottom-line impacts.

Alliances through M\&A do not always lead to significant market reactions. This implies that investors take time and are willing to review such changes. But those that are significant have a high likelihood of being perceived positively; in fact, more than two thirds are considered positive by investors. This might be due to economies of scale or scope that result from mergers and alliances that are so important for the telecoms business. Geographically, telecom service 
providers in US, Singapore and Italy are more likely to face market reactions to M\&A events. Further, in the US market, 2 out of every 3 events are negative while in Singapore 3 out of 4 are negative. In contrast, Italy once again is more positive where 4 out of 5 events related to M\&A are regarded positive.

Changes to company structure or its leadership are viewed by the market in a balanced manner. While almost half of the changes were viewed positively, slightly less than half had a negative impact. The overall proportion of such activities though is smaller though, which means that investors are less likely to react to such changes especially as compared to technology or business model changes.

The above results would be useful for telecoms companies as they consider changes and restructuring to remain relevant. Operators expanding their business to other parts of the world can also use the results to understand the different nature of the overseas markets and how to develop more considered strategies based on reactions they are likely to encounter from investors.

\section{References}

Aggarwal, N., Dai, Q., and Walden, E.A."Do Markets Prefer for an Open or Proprietary Standards for XML standardization- An Event Study" International Journal of Electronic Commerce, 11(1): 117- 136, 2006.

Bailey, W., Mao, C.X., and Sirodom, K. "Investment Restrictions and Cross Border Flow of Information: Some Empirical Evidence", Working Paper, Johnson Graduate School of Management, Cornell University, 2004.

Bollerslev, T., "Generalized Autoregressive Conditional Heteroskedasticity, Journal of Econometrics", Journal of Econometrics, 31: 307-327, 1986.

Cohen-Meidan, M., "The effects of standardization process on competition: An event study of the standardization process in the US cable modem market", Telecommunications Policy, 31(10-11): 2007.

Cont, R., "Empirical Properties of Asset Returns: Stylized Facts and Statistical Issues", Quantitative Finance, 1: 223-236, 2001.

Eisenach, J.A., and Lawengrab, P. "Economic Implications of the FCC's UNE Decision: An Event Analysis Study", Working paper series, SSRN (http://papers.ssrn.com/sol3/papers.cfm?abstract id=1260430 ), 2003.

Kushida, K.E., “Japan's Telecommunications Regime Shift: Understanding Japan's Potential Resurgence", BRIE working paper, 170, 2005.

Madden, T.K., Fehl, F., and Fournier, S. "Brands Matter: An Empirical Demonstration of the Creation of Shareholder Value Through Branding", Journal of the Academy of Marketing Science, 34(2): 224-235, 2006.

Roy, R. "Market Efficiency Effects of Regulation Fair Disclosure," Working Paper, Stern School of Business, NYU, 2002.

Sanchez-Lorda, P. "Stock Market Response to Acquisitions and Alliances in the European Telecom Industry: An Information Asymmetry Perspective”, ETRI Journal, 28(5): 638-647, 2006. 
Singh, H., Sethi, Vijay, Sethi, Vikram, "Changing Inside, Watching Outside: Understanding Business Model Adaptations to Guide Information Technology Decisions", Twenty-Sixth International Conference on Information Systems, 629-643, 2005.

\footnotetext{
${ }^{\mathrm{i}}$ The advantage of specifying a GARCH specification is that during bubble effect, such as IT bubble, the conditional variance, $\sigma_{t}^{2}=k+\alpha a_{t-1}^{2}+\beta \sigma_{t-1}^{2}==\Omega\left(a_{t-i}^{2}, \sigma_{t-i}^{2}\right) \forall i=1,2, \ldots$ will be inflated in the face of a bubble resulting in high and persistent volatility arising out of shocks (also referred to as innovations), $a_{t}$, through the absorption parameter $\alpha$ and persistence parameter $\beta$ so that conditional variance of the stock, $\sigma_{t}^{2}$ remains high for high innovations, $a_{t}$ s. Thus the impact of $\lambda_{i} s$ are net of impact of NASDAQ index as well as subsequent inflated volatility (Figure VII \& VIII) of the particular stocks return in the face of a post-bubble scenario.
} 